Check for updates

Cite this: Chem. Sci., 2019, 10, 6024

- All publication charges for this article have been paid for by the Royal Society of Chemistry

Received 16th March 2019

Accepted 31st May 2019

DOI: $10.1039 /$ c9sc01309a

rsc.li/chemical-science

\section{Bio-based building blocks from 5-hydroxymethylfurfural via 1-hydroxyhexane- 2,5-dione as intermediate}

\author{
Bartosz Wozniak, (D) Sergey Tin (D) and Johannes G. de Vries (DD*
}

The limits to the supply of fossil resources and their ever increasing use forces us to think about future scenarios for fuels and chemicals. The platform chemical 5-hydroxymethyl-furfural (HMF) can be obtained from biomass in good yield and has the potential to be converted in just a few steps into a multitude of interesting products. Over the last 20 years, the conversion of HMF to 1-hydroxyhexane2,5-dione (HHD) has been studied by several groups. It is possible to convert HMF into HHD by hydrogenation/hydrolytic ring opening reaction in aqueous phase using various heterogeneous and homogeneous catalysts. This review addresses both the state of the art of HHD synthesis, including mechanistic aspects of its formation, as well as the recent progress in the application of HHD as a building block for many useful chemicals including pyrroles, cyclopentanone derivatives and triols.

\section{HMF as a platform chemical}

Extensive utilisation of fossil fuel reserves and as a consequence of this the global warming issues are currently the major challenges our modern society needs to face..$^{1-3}$ Considering the fact that more than $90 \%$ of chemicals our lives depend upon, such as polymers, pharmaceuticals, detergents or food additives are currently derived from crude oil, ${ }^{4}$ development of new sustainable technologies with the aim to produce chemicals from renewable resources is crucial. Biomass is the most

Leibniz-Institut für Katalyse e.V., Universität Rostock, Albert-Einstein-Str.29a, 18059 Rostock, Germany.E-mail: Johannes.deVries@catalysis.de attractive, low-cost feedstock produced by nature and therefore readily available around the world. ${ }^{5-9}$ Unlike other renewable sources like solar, wind, hydroelectric and geothermal energies, biomass contains organic carbon and has a great potential to substitute oil and coal in the production of fuels and chemicals. Lignocellulosic biomass is one of the most abundant feedstock widely available in the form of nonedible forestry or agro waste. ${ }^{10}$ Depending on the class and origin of the plant, polymeric lignocellulose is comprised of three basic materials in various ratios (i) $30-50 \mathrm{wt} \%$ cellulose, (ii) $20-40 \mathrm{wt} \%$ hemicellulose and (iii) 10-20\% lignin. ${ }^{11}$

Special attention has been given to the conversion of lignocellulose or its constituents to widely applicable so-called

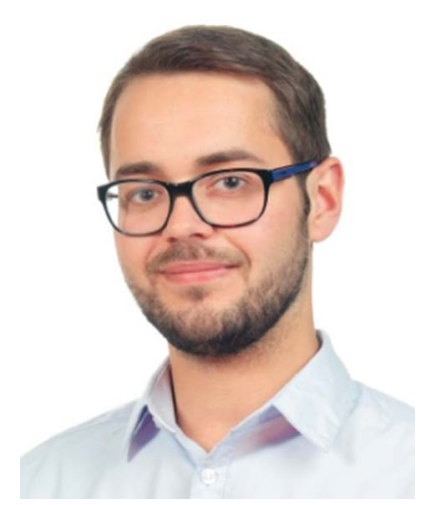
Ph.D degree (2019) in the field of organic chemistry and catalysis.
Currently, he is working on the preparation of chemical building Ph.D degree (2019) in the field of organic chemistry and catalysis.
Currently, he is working on the preparation of chemical building Ph.D degree (2019) in the field of organic chemistry and catalysis.
Currently, he is working on the preparation of chemical building
blocks from renewables.

Bartosz Wozniak received his B.S (2013) and M.S (2015) degrees in biological chemistry from the Adam Mickiewicz University, Poznan, Poland, under the supervision of Prof. Bogdan Marciniec. After a four months research project with Prof. Vidar Jensen in Bergen, Norway, he joined the department of Prof. Johannes de Vries at the LIKAT, Rostock, Germany, where he recently obtained his

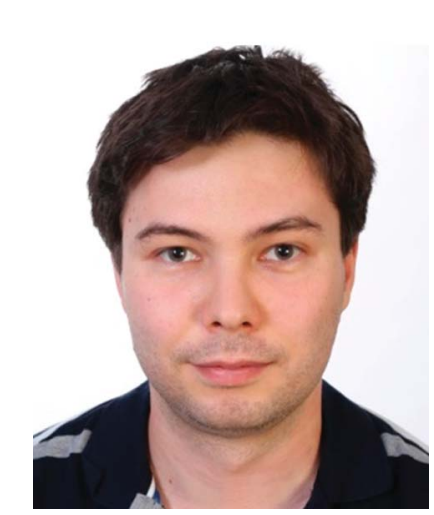

Sergey Tin was born in 1989 in Kazakhstan. He completed his masters in chemistry with an external placement in 2012 at the University of St Andrews. In 2016 he obtained his PhD degree with a thesis entitled "Rh catalysed hydrogenation of enamines: factors affecting the rate and enantioselectivity" in the same place. In 2017 he moved to Germany and started a post-doc in LIKAT. Currently he works as a group leader in the department of Prof. Johannes $G$. de Vries. 
<smiles>O=Cc1ccc(CO)o1</smiles>

Fig. 1 Chemical structure of 5-hydroxymethylfurfural (HMF).

Platform Chemicals of high industrial potential (Fig. 1). ${ }^{8} \mathrm{~A}$ platform chemical is an intermediate molecule, which is produced from biomass at a competitive cost and can be transformed to a sufficient number of valuable intermediates.

5-Hydroxymethylfurfural (HMF) is one of the most valuable platform chemicals. Although it was initially not included in the "Top 10" list of chemicals obtained from biomass in the report made for the U.S. Department of Energy, ${ }^{5}$ Bozell did include it in his report on the top ten chemical from biomass ten years later. ${ }^{12} \mathrm{HMF}$ is a furan-type compound which has retained all six carbons from the hexose and contains two functional groups: an aldehyde and a hydroxymethyl group (Fig. 1). It can be obtained in relatively high yields from fructose by dehydration or in lower yields from glucose or even cellulose. ${ }^{13-16}$

The first reports on HMF synthesis by Düll ${ }^{17}$ and Kiermayer ${ }^{18}$ can be dated back to 1895. Since then, a significant growth in interest on HMF formation and applicability resulted in an enormous number of publications with an evident peak in the last years. As a consequence of this, recent advances in the synthesis and utilisation of HMF were reviewed by several groups. ${ }^{13-16,19-21} \mathrm{HMF}$ is a very valuable building block with a wide range of applications. Scheme 1 provides an overview of the conversion of HMF into the most useful follow-up products, such as caprolactam ${ }^{22} 2,5$-furandicarboxylic acid ${ }^{23,24}$ or adipic $\operatorname{acid}^{25,26}$ Two main challenges remain for the large-scale production of HMF. One is the use of readily available cheap feedstocks such as cellulose, starch or preferably lignocellulose to reduce the cost price to an acceptable level. Currently, HMF is only produced on a scale of a few hundred tons per year by AvaBiochem as a side product of sugar carbonisation and hence is

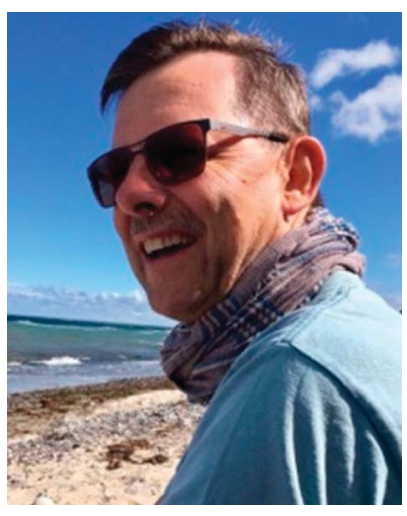

Johannes $G$. de Vries received his PhD from the University of Groningen in 1979. After a postdoc at Brandeis University, Waltham, USA, his first job was as a medicinal chemist with Sandoz in Vienna and in London. From 1988-2013 he worked for DSM in Geleen, The Netherlands, lastly as a Principal Scientist in the area of Homogeneous Catalysis. From 1999-2018 he was parttime professor at the University of Groningen. In 2014 he became Department Head Catalysis with Renewables at the Leibniz Institute for Catalysis in Rostock, Germany. In 2013 he received the Paul N. Rylander Award for outstanding contributions in the field of catalysis as it applies to organic synthesis.

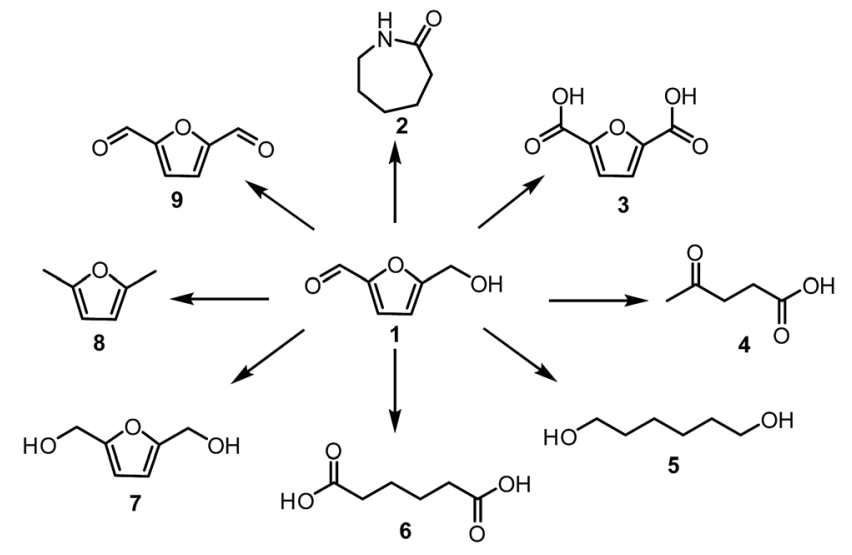

Scheme 1 Conversion of HMF to valuable chemicals.

relatively expensive. ${ }^{27}$ The other issue is the instability of HMF, which makes its isolation in high yields problematic. ${ }^{28}$ To deal with this issue Avantium developed a process for the production of the much more stable methyl ether of $\mathrm{HMF}^{29}$ and Mascal developed a process for the production of stable 5chloromethyl-furfural in good yield, even from cellulose. ${ }^{30}$

\section{Synthesis of 1-hydroxyhexane-2,5- dione}

Recently, the synthesis of 1-hydroxyhexane-2,5-dione (HHD) from HMF has attracted the interest of several groups. HHD is a ring-opened product, which has retained all six carbons that were present in HMF (Fig. 2). Moreover, the presence of two carbonyl groups and one hydroxyl group in the alkyl chain makes it an appropriate precursor for the synthesis of valuable follow-up products.

It is possible to convert HMF into HHD by hydrogenation/ hydrolytic ring opening reaction in aqueous phase using various heterogeneous and homogeneous catalysts. ${ }^{22,31-45}$ In only four of these the isolation and purification of HHD was reported..$^{37,42,45,47}$ In this chapter, different catalytic strategies for the synthesis of HHD from HMF as well as mechanistic aspects of this transformation will be discussed.

\subsection{Hydrogenation/hydrolytic ring opening of HMF catalysed by heterogeneous catalysts}

The first publication regarding HHD synthesis dates back to 1991. ${ }^{31}$ Descotes and co-workers reported the Pt/C catalysed formation of HHD in water containing $15 \mathrm{wt} \%$ of oxalic acid. The reaction was carried out at $140{ }^{\circ} \mathrm{C}$ under 30 bar of $\mathrm{H}_{2}$ for 3 hours resulting in $60 \%$ conversion to HHD. When 70 bar of $\mathrm{H}_{2}$<smiles>CC(=O)CCC(=O)CO</smiles>

Fig. 2 Chemical structure of 1-hydroxyhexane-2,5-dione (HHD). 
were applied, a decrease in HHD yield was observed (to 51\%). A separate experiment under the same conditions, but in the presence of $75 \mathrm{wt} \%$ oxalic acid in water afforded only $31 \%$ of HHD. In addition to these experiments a possible mechanism for the conversion of HMF to HHD was proposed (Scheme 2). Under acidic conditions HMF undergoes rehydration followed by ring-opening to form the stable intermediate 10, which was confirmed by ${ }^{13} \mathrm{C}$ NMR. In a subsequent step, the double bond and aldehyde functionalities are hydrogenated selectively in the presence of the ketone groups leading to the formation of HHD. The group of van Bekkum investigated hydrogenolysis of HMF in water using $10 \% \mathrm{Pd} / \mathrm{C}$ under mild reaction conditions ( 1 bar of $\left.\mathrm{H}_{2}, 60{ }^{\circ} \mathrm{C}\right) .{ }^{32}$ The experiments showed that adding small amount of concentrated $\mathrm{HCl}$ was necessary to obtain HHD. The reported HHD yield after 410 min was $28 \%$, at $98 \%$ conversion of HMF. The main product obtained under these conditions was 2,5-bishydroxymethylfuran (BHMF) (47\%). Interestingly, when the reaction was performed in a biphasic solvent system, consisting of water and toluene in a $2: 1$ ratio, the yield of HHD improved considerably to $68 \%$.

Heeres, de Vries and co-workers reported the use of a bimetallic $\mathrm{Rh}-\mathrm{Re} / \mathrm{SiO}_{2}$ catalyst for the hydrogenation of $\mathrm{HMF}$ to HHD. ${ }^{22}$ Initially, the reaction was carried out at $120{ }^{\circ} \mathrm{C}$ using $10 \mathrm{~mol} \%$ of the catalyst in water at 10 bar of $\mathrm{H}_{2}$ for 1 hour. After this time, the pressure was raised to 80 bar of $\mathrm{H}_{2}$ and the reaction was stirred for 17 hours resulting in $81 \%$ selectivity towards HHD at full conversion of the starting material.

Ohyama et al. reported the hydrogenation of HMF catalysed by gold nanoparticles in aqueous solutions. ${ }^{33}$ Depending on the metal oxide that was used as a support, BHMF and/or HHD were obtained by applying 38 bar of $\mathrm{H}_{2}$ at $140{ }^{\circ} \mathrm{C}$. The highest HHD yield of $57 \%$ was achieved using $1 \mathrm{wt} \% \mathrm{Au} / \mathrm{TiO}_{2}$ combined with $4 \mathrm{wt} \%$ of $\mathrm{SO}_{3}$, which acted as a Brønsted acid. A later publication by the same group reported a $60 \%$ yield of $\mathrm{HHD}$ at $81 \% \mathrm{HMF}$ conversion in the reaction catalysed by gold nanoparticles supported on $\mathrm{Nb}_{2} \mathrm{O}_{5} \cdot{ }^{34}$ For this reaction, higher pressures (80 bar of $\mathrm{H}_{2}$ ) and addition of catalytic amounts of $\mathrm{H}_{3} \mathrm{PO}_{4}$ were required. In addition, the authors suggested an alternative route for HHD formation (Scheme 3). In the first step, HMF is hydrogenated to BHMF followed by the hydrolytic ring-opening to 1-hydroxyhex-3-en-2,5-dione (11) in the second step and the

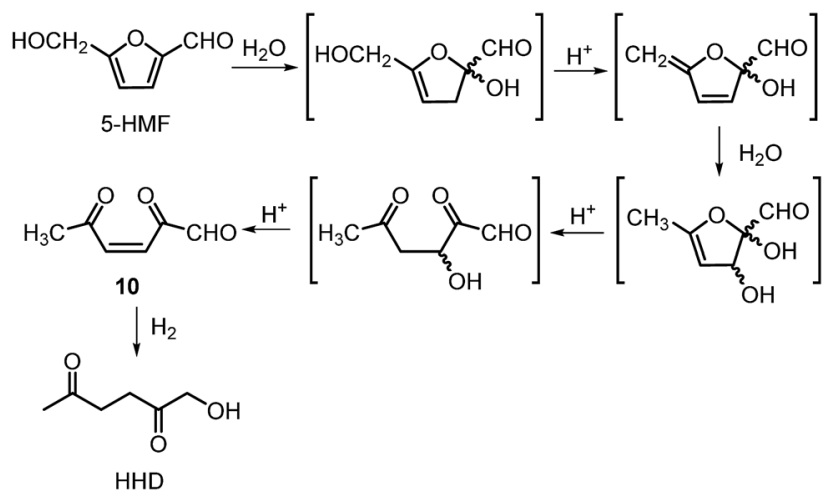

Scheme 2 Proposed pathway for HHD synthesis by Descotes.

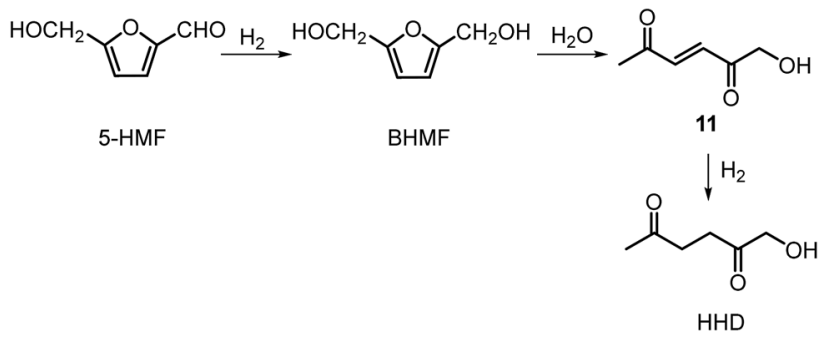

Scheme 3 Conversion of HMF to HHD, as proposed by Satsuma.

reduction of $\mathbf{1 1}$ to $\mathrm{HHD}$ in the last step. In 2014, the group of Jérôme came to the same conclusions concerning the mechanism. ${ }^{35}$ They were able to convert BHMF to HHD in $60 \%$ yield in a reaction catalysed by $2 \mathrm{wt} \% \mathrm{Pd} / \mathrm{C}$ in water at $120{ }^{\circ} \mathrm{C}$ under 10 bar of $\mathrm{H}_{2}$ and 30 bar of $\mathrm{CO}_{2}$. The addition of $\mathrm{CO}_{2}$ appears to be necessary to obtain HHD through the formation of carbonic acid, which provides acidic conditions. Further investigations revealed an increase in $\mathrm{HHD}$ yield to $77 \%$ when the experiment was performed with $7.5 \mathrm{wt} \% \mathrm{Pd} / \mathrm{C}$ and $\mathrm{HMF}$ was used as a starting material. It should be noted that different $\mathrm{H}_{2} / \mathrm{CO}_{2}$ ratios and higher catalyst loadings showed no significant improvement. The authors also examined direct conversion of fructose and inulin to HHD for the first time. In the first step, carbohydrates are converted to HMF by heating in water at $150{ }^{\circ} \mathrm{C}$ under 40 bar of $\mathrm{CO}_{2}$ followed by hydrogenation/ hydrolytic ring opening of $\mathrm{HMF}$ after addition of $\mathrm{Pd} / \mathrm{C}$ (7.5 wt\%) and applying 10 bar of $\mathrm{H}_{2}$. The overall HHD yields were $36 \%$ and $15 \%$ from fructose and inulin respectively. In an extended work by the same group, the combination of both solid catalysts Amberlyst-15 and $\mathrm{Pd} / \mathrm{C}$ was evaluated for the synthesis of HHD. ${ }^{36}$ Compared to the method described earlier, the reactions were carried out in wet THF at $80{ }^{\circ} \mathrm{C}$. After optimisation, a 77\% HHD yield was achieved after 15 hours by the use of $5.5 \mathrm{wt} \% \mathrm{Pd} / \mathrm{C}$ and $20 \mathrm{wt} \%$ Amberlyst-15 at 50 bar of $\mathrm{H}_{2}$. Again, this catalytic system was demonstrated to be efficient for the conversion of fructose and inulin towards HHD in 55\% and $27 \%$ yields respectively.

$\mathrm{Xu}$ and co-workers established the hydrogenation of HMF in acidic water $\left(\mathrm{H}_{3} \mathrm{PO}_{4}, \mathrm{pH} 2-3\right)$ under 1 bar of $\mathrm{H}_{2}$ at reflux. ${ }^{37}$ They isolated the product by column chromatography in $37 \%$ yield in the form of a yellow solid. In 2017, Yang and co-workers used palladium supported on acidic $\mathrm{Nb}_{2} \mathrm{O}_{5}$ for the hydrogenation of HMF in water. ${ }^{38}$ The highest selectivity towards HHD was $90 \%$ under 10 bar of $\mathrm{H}_{2}$ after $2 \mathrm{~h}$, however only $21 \%$ conversion of HMF was obtained. After optimising the conditions, $73 \%$ selectivity towards HHD was achieved at 97\% conversion after 6 hours at $140{ }^{\circ} \mathrm{C}$ and 40 bar of $\mathrm{H}_{2}$. In addition, a $\mathrm{Pd} / \mathrm{Ni}_{2} \mathrm{O}_{5}-400$ catalyst could be recycled up to 4 times without apparent loss in activity.

\subsection{Hydrogenation/hydrolytic ring opening of HMF catalysed by homogeneous catalysts}

Only a limited number of studies is available on the conversion of HMF to HHD using homogeneous catalysts. Homogeneous catalysts seem to perform better than the heterogeneous 


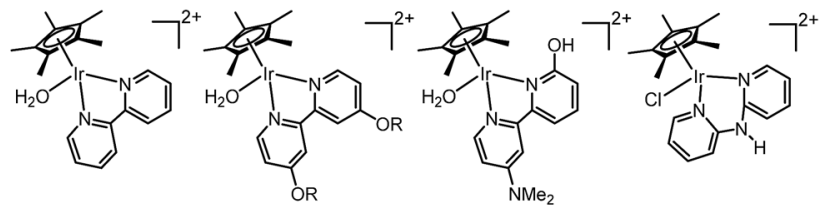

[lr]-1 $[l r]-2, R=H$
$[l r]-3, R=M e$

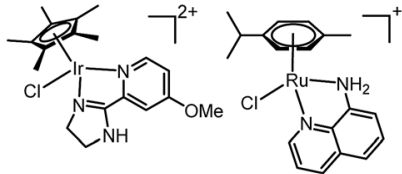

$[1 \mathrm{r}]-6$

[Ru]-1

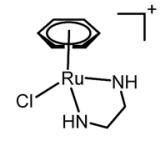

[Ru]-2 $[\mid r]-5$

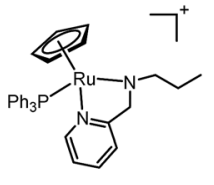

[Ru]-3
Fig. 3 Iridium- and ruthenium-based complexes for the synthesis of HHD.

catalysts with respect to HHD yields, shorter reaction times and milder conditions (temperature, pressure). Especially, iridium and ruthenium-based metal complexes were found to be efficient in HMF hydrogenation/transfer hydrogenation (Fig. 3). Concerning the use of homogeneous catalyst for the synthesis of HHD, limitations appear to lie mainly in the requirements of water solubility and stability under acidic conditions. Zhang and co-workers were the first to apply a homogeneous catalyst in HHD synthesis. ${ }^{39}$ Hydrogenation/hydrolytic ring opening of HMF was performed in aqueous solution using bipyridine coordinated $\mathrm{Cp}^{*}-\mathrm{Ir}$ complexes $\left(\mathrm{Cp}^{*}=\right.$ pentamethylcyclopentadiene) at different temperatures $\left(110-130{ }^{\circ} \mathrm{C}\right)$ and hydrogen pressures (5-20 bar of $\mathrm{H}_{2}$ ). The highest HHD yield of $86 \%$ at full conversion of the starting material was obtained with $0.26 \mathrm{~mol} \%$ [Ir]-1 at $120{ }^{\circ} \mathrm{C}$ after 2 hours at 7 bar $\mathrm{H}_{2}$.

They also performed detailed mechanistic studies using deuterium labelling. Two possible mechanistic pathways were proposed through key intermediate 12 (Scheme 4), which is consistent with the mechanism proposed by Jérome. ${ }^{35}$ Pathway A assumes a two-steps reaction to generate 12 from BHMF with an initial water addition followed by water-elimination, whereas pathway B proceeds through a one-step hydrolysis process. In the next step, intermediate $\mathbf{1 2}$ is hydrolysed to $\alpha, \beta$-unsaturated di-carbonyl compound 11, which then undergoes hydrogenation to form HHD. Hydrogenation of BHMF in $\mathrm{D}_{2} \mathrm{O}$ catalysed by [Ir]-1 leads to the conclusion that pathway $\mathrm{B}$ is more plausible based on the composition of the deuterated HHD ion fragment (GC-MS analysis) and statistical calculations.

Singh and co-workers reported water soluble 8-aminoquinoline coordinated arene-ruthenium(II) complexes for the conversion of biomass-derived furans. ${ }^{40}$ Moreover, formic acid was successfully applied as a hydrogen source. By the use of 12 eq. of formic acid relative to the substrate in the presence of $1 \mathrm{~mol} \%$ of [Ru]-1, a moderate selectivity to HHD of $52 \%$ was obtained from HMF at $80{ }^{\circ} \mathrm{C}$ after 48 hours. Apart from HHD, other products were also formed, such as levulinic acid $(21 \%)$ and 3-hydroxy-2,5-hexanedione (27\%). A later publication by the same group reported the use of $\mathrm{Ru}(\mathrm{II})$-arene complexes containing ethylenediamine-based ligands for the synthesis of diketones. ${ }^{41}$ However, a lower HHD selectivity (44\%) was obtained after 8 hours in the reaction catalysed by $5 \mathrm{~mol} \%$ of [Ru]2 at $100{ }^{\circ} \mathrm{C}$ in the presence of formic acid. In addition, the direct conversion of fructose to HHD was investigated. The optimised conditions afforded $27 \%$ selectivity to HHD and $51 \%$ to LA. However, longer reaction times $(16 \mathrm{~h})$ led to a significantly higher HHD selectivity of $87 \%$.

In 2016, Fu and co-workers made an important step forward in the synthesis of HHD from HMF. ${ }^{42}$ They evaluated a series of CP*Ir(III) complexes bearing bipyridine ligands with either electron-donating or electron-withdrawing groups at different positions. They found that the combined influence of temperature and $\mathrm{pH}$ is the most relevant factor for the formation of HHD in high yields. Catalyst screening showed relatively high HHD selectivities of around $70 \%$ with $0.01 \mathrm{~mol} \%$ of [Ir]-2 or [Ir]3 complexes in aqueous formate buffer solution (FBS, $\mathrm{pH}=2.5$ ) at $120^{\circ} \mathrm{C}$ in 2 hours. Interestingly, an increase in temperature to $130{ }^{\circ} \mathrm{C}$ led to remarkably higher HHD selectivity of up to $95 \%$. A large-scale experiment was performed with the aim to isolate HHD and to test the recyclability of the catalyst. The authors reported an isolated HHD yield of $85 \%$ ( $92 \%$ GC yield) after the

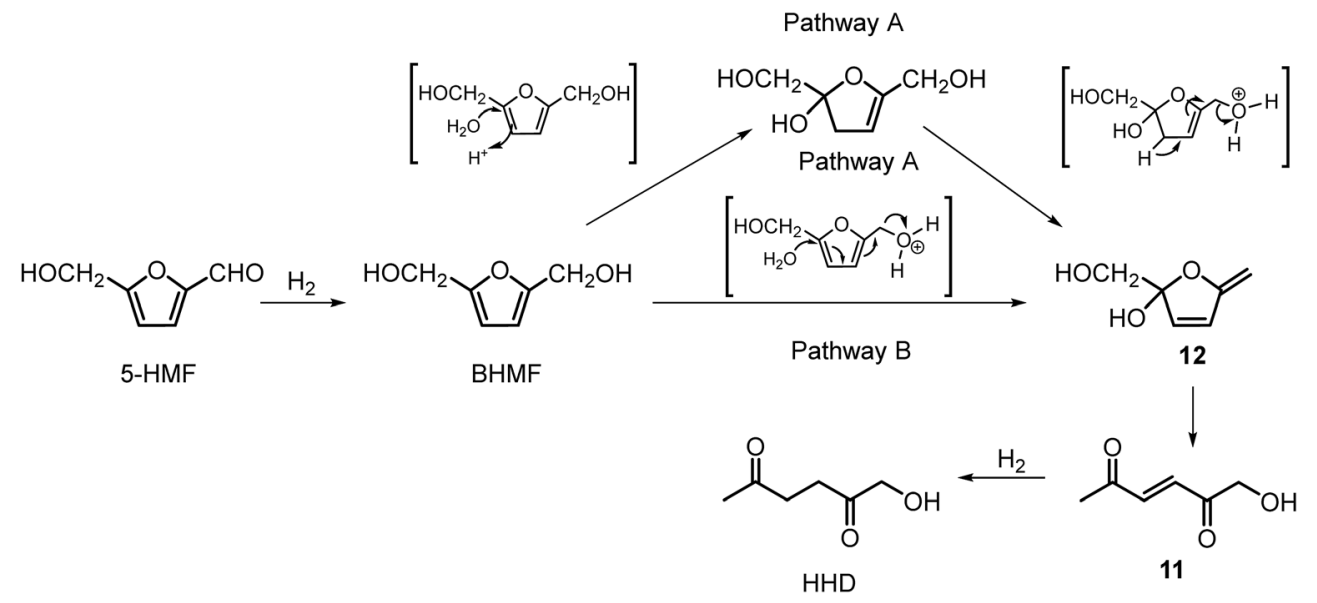

Scheme 4 Proposed pathways for HHD synthesis by Zhang. 




Scheme 5 Proposed pathways for HHD synthesis by Fu.

first cycle under the optimised conditions. In a recycling experiment a decrease in activity of the catalyst was observed and HHD was produced in $70 \%$ yield. Additionally, another insight to the mechanism of HHD formation was proposed as depicted in Scheme 5. In the first step, HMF is hydrogenated to BHMF as was postulated previously. In the next step, two alternative routes were assessed for the conversion of BHMF to HHD. The formation of 5-methylfurfuryl alcohol as an intermediate is an important distinction between the two catalytic routes. However, when 5-methylfurfuryl alcohol was used as a starting material under the same experimental conditions, the only product obtained was 2,5-hexanedione. On the basis of this result, pathway A was indicated to be the more likely one.

With the same catalyst ([Ir]-2, $0.1 \mathrm{~mol} \%)$, Xu et al. demonstrated the hydrogenation of HMF in the presence of $5 \mathrm{~mol} \%$ $\mathrm{Al}_{2}\left(\mathrm{SO}_{4}\right)_{3}$, which provides acidic conditions in water by generating sulfuric acid..$^{43}$ A HHD selectivity of $77 \%$ was reported in aqueous solution at 30 bar of $\mathrm{H}_{2}$ and $130{ }^{\circ} \mathrm{C}$ after 4 hours.

In another publication from Zhang and co-workers, a new series of half-sandwich $\mathrm{Cp}^{*}$-Ir(III) complexes were tested for the synthesis of HHD from HMF. ${ }^{44}$ Promising results were achieved using complex [Ir]-4 bearing a bipyridine ligand containing both $o$-hydroxyl and $p$ - $N$-dimethylamino groups. The effect of the catalyst loading, $\mathrm{pH}$ and pressure was investigated. At a catalyst loading of $0.0008 \mathrm{~mol} \%$ hydrogenation of $\mathrm{HMF}$ resulted in $67 \%$ selectivity towards HHD at $88 \%$ conversion after 6 hours in acidic water $(\mathrm{pH}=3.4)$ at $120^{\circ} \mathrm{C}$ under 35 bar of

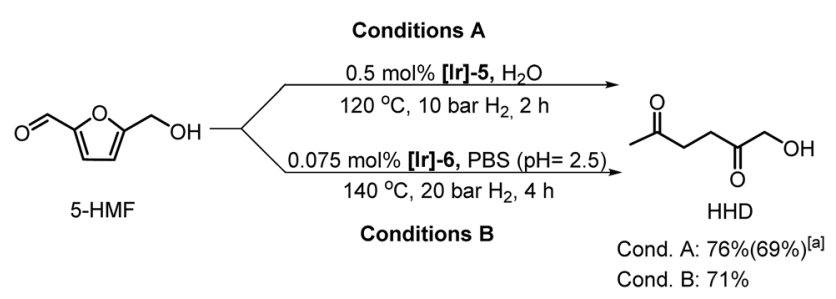

Scheme 6 Conversion of HMF to HHD under various reaction conditions; " asolated yield.
$\mathrm{H}_{2}$. Based on this experiment, the TOF $\left(31560 \mathrm{~h}^{-1}\right)$ and TON (70 800) were calculated. The same catalyst was tested for the transfer hydrogenation of HMF using 2 eq. of formic acid at $120{ }^{\circ} \mathrm{C}$. This catalytic system provided $60 \%$ HHD yield in the presence of $0.005 \mathrm{~mol} \%$ of [Ir]-4 after 2 hours.

De Vries and co-workers evaluated a series of air- and moisture-stable iridium complexes for the hydrogenation/ hydrolytic ring opening of HMF. ${ }^{45}$ Depending on the reaction conditions, the highest HHD yields were obtained in the reactions catalysed by half-sandwich iridium complexes [Ir]-5 and [Ir]-6 (Scheme 6). Up to 76\% selectivity towards HHD was achieved when HMF was reduced in water in the presence of $0.5 \mathrm{~mol} \%$ [Ir]-5 catalyst at $120{ }^{\circ} \mathrm{C}$ under 10 bar of $\mathrm{H}_{2}$ for $2 \mathrm{~h}$ (Scheme 6, conditions A). The major by-product formed under these conditions was an insoluble brown polymeric material, presumably humins, formation of which was also reported with other catalysts. ${ }^{35,42}$ In addition, the isolation of HHD in 69\% overall yield was reported. Moreover, the full characterisation of HHD was reported including its crystal structure, obtained by Xray diffraction analysis (Fig. 4).

Interestingly, the utilisation of phosphate buffer solution (PBS, $\mathrm{pH}=2.5$ ) as the reaction medium allowed processing at lower catalyst loading $(0.075 \mathrm{~mol} \%)$ without significant losses in selectivity towards HHD; $71 \%$ HHD was obtained in the presence of [Ir]-6 catalyst (Scheme 6, conditions B). In another

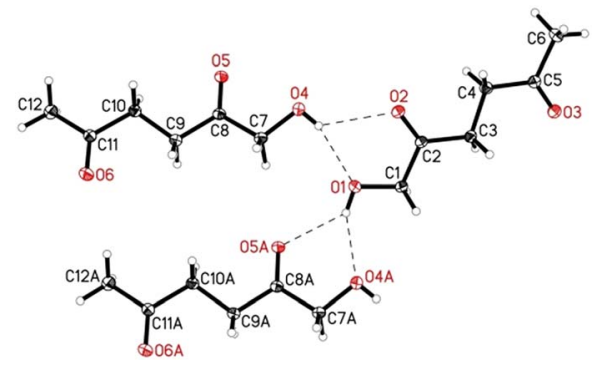

Fig. 4 ORTEP representation of HHD showing intermolecular $\mathrm{O}-\mathrm{H} \cdots \mathrm{O}$ hydrogen bonds. 
Table 1 Catalytic processes reported for the synthesis of HHD

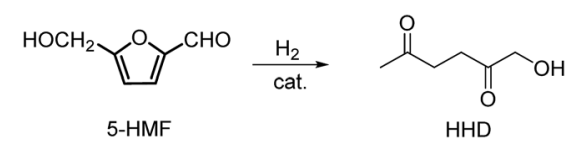

\begin{tabular}{|c|c|c|c|c|}
\hline Catalyst (cat. loading) & Conditions & Conv. $(\%)$ & Yield $(\%)$ & Ref. \\
\hline $\mathrm{Pt} / \mathrm{C}(0.5$ wt $\%)$ & $15 \mathrm{~mol} \% \mathrm{C}_{2} \mathrm{H}_{2} \mathrm{O}_{4}, 140{ }^{\circ} \mathrm{C}, \mathrm{H}_{2} \mathrm{O}, 30$ bar $\mathrm{H}_{2}, 3 \mathrm{~h}$ & na & 60 & 27 \\
\hline $\mathrm{Pd} / \mathrm{C}(50 \mathrm{wt} \%)$ & $12.5 \mathrm{~mol} \% \mathrm{HCl}, 60^{\circ} \mathrm{C}, \mathrm{H}_{2} \mathrm{O}:$ toluene $(2: 1), 1$ bar $\mathrm{H}_{2}, 4 \mathrm{~h}$ & 97 & 68 & 28 \\
\hline $\mathrm{Rh}-\mathrm{Re} / \mathrm{SiO}_{2}(10 \mathrm{~mol} \%)$ & $120^{\circ} \mathrm{C}, \mathrm{H}_{2} \mathrm{O}, 10$ bar $\mathrm{H}_{2}$ for $1 \mathrm{~h}$, then 80 bar $\mathrm{H}_{2}$ for $17 \mathrm{~h}$ & 100 & 81 & 22 \\
\hline $\mathrm{Au} / \mathrm{TiO}_{2}(1 \mathrm{wt} \%)$ & $4 \mathrm{wt} \% \mathrm{SO}_{3}, 140{ }^{\circ} \mathrm{C}, \mathrm{H}_{2} \mathrm{O}, 38$ bar $\mathrm{H}_{2}, 4 \mathrm{~h}$ & 84 & 57 & 29 \\
\hline $\mathrm{Au} / \mathrm{Nb}_{2} \mathrm{O}_{5}(1 \mathrm{wt} \%)$ & $8.5 \mathrm{mM} \mathrm{H}_{3} \mathrm{PO}_{4}, 140^{\circ} \mathrm{C}, \mathrm{H}_{2} \mathrm{O}, 80$ bar $\mathrm{H}_{2}, 12 \mathrm{~h}$ & 81 & 60 & 30 \\
\hline $\mathrm{Pd} / \mathrm{C}(7.5 \mathrm{wt} \%)$ & $120^{\circ} \mathrm{C}, \mathrm{H}_{2} \mathrm{O}, 10$ bar $\mathrm{H}_{2}, 30$ bar $\mathrm{CO}_{2}, 15 \mathrm{~h}$ & 100 & 77 & 31 \\
\hline $\mathrm{Pd} / \mathrm{C}(5.5 \mathrm{wt} \%)$ & $20 \mathrm{wt} \%$ Amberlyst- $15,80{ }^{\circ} \mathrm{C}$, THF (containing $3.8 \mathrm{wt} \% \mathrm{H}_{2} \mathrm{O}$ ), $50 \mathrm{bar}_{2}, 15 \mathrm{~h}$ & 100 & 77 & 32 \\
\hline $\mathrm{Pd} / \mathrm{AC}(5 \mathrm{wt} \%)$ & Reflux, $\mathrm{H}_{2} \mathrm{O}, 1$ bar $\mathrm{H}_{2}, 72 \mathrm{~h}$ & na & $37^{a}$ & 33 \\
\hline $\mathrm{Pd} / \mathrm{Nb}_{2} \mathrm{O}_{5}(2 \mathrm{wt} \%)$ & $140{ }^{\circ} \mathrm{C}, \mathrm{H}_{2} \mathrm{O}, 40$ bar $\mathrm{H}_{2}, 6 \mathrm{~h}$ & 93 & 73 & 34 \\
\hline$[\mathbf{I r}]-\mathbf{1}(0.26 \mathrm{~mol} \%)$ & $120^{\circ} \mathrm{C}, \mathrm{H}_{2} \mathrm{O}, 7$ bar $\mathrm{H}_{2}, 2 \mathrm{~h}$ & 100 & 86 & 35 \\
\hline [Ru]-1 (1 mol\%) & $80{ }^{\circ} \mathrm{C}, \mathrm{H}_{2} \mathrm{O}, 12$ eq. $\mathrm{HCOOH}, 48 \mathrm{~h}$ & 100 & 52 & 36 \\
\hline$[\mathbf{R u}]-2(5 \mathrm{~mol} \%)$ & $100^{\circ} \mathrm{C}, \mathrm{H}_{2} \mathrm{O}, 12$ eq. $\mathrm{HCOOH}, 8 \mathrm{~h}$ & 100 & 44 & 37 \\
\hline$[\mathbf{I r}]-2(0.01 \mathrm{~mol} \%)$ & $130^{\circ} \mathrm{C}, \mathrm{FBS}(\mathrm{pH}=2.5), 2 \mathrm{~h}$ & 100 & $92(85)^{a}$ & 38 \\
\hline$[\mathbf{I r}]-2(0.1 \mathrm{~mol} \%)$ & $5 \mathrm{~mol} \% \mathrm{Al}_{2}\left(\mathrm{SO}_{4}\right)_{3}, 130^{\circ} \mathrm{C}, \mathrm{H}_{2} \mathrm{O}, 30$ bar $\mathrm{H}_{2}, 4 \mathrm{~h}$ & 100 & 77 & 39 \\
\hline$[\mathrm{Ir}]-4(0.0008 \mathrm{~mol} \%)$ & $120^{\circ} \mathrm{C}, \mathrm{H}_{2} \mathrm{O}(\mathrm{pH}=3.4), 35$ bar $_{2}, 6 \mathrm{~h}$ & 88 & 67 & 40 \\
\hline$[\mathbf{I r}]-5(0.5 \mathrm{~mol} \%)$ & $120^{\circ} \mathrm{C}, \mathrm{H}_{2} \mathrm{O}, 10$ bar $\mathrm{H}_{2}, 2 \mathrm{~h}$ & 100 & $76(69)^{a}$ & 41 \\
\hline$[\mathbf{I r}]-6(0.075 \mathrm{~mol} \%)$ & $140{ }^{\circ} \mathrm{C}$, PBS $(\mathrm{pH}=2.5), 60$ bar $\mathrm{H}_{2}, 1 \mathrm{~h}$ & 100 & $71^{a}$ & 42 \\
\hline$[\mathbf{R u}]-3(5 \mathrm{~mol} \%)$ & $120^{\circ} \mathrm{C}, \mathrm{H}_{2} \mathrm{O}, 12$ eq. $\mathrm{HCOOH}, 12 \mathrm{~h}$ & 96 & $69(42)^{a}$ & 43 \\
\hline
\end{tabular}

publication by the same group, the authors aimed to perform a large-scale synthesis of HHD under the optimised conditions in PBS. $^{46}$ The reaction was conducted under 60 bar of $\mathrm{H} 2$ resulting in the full conversion of HMF after 1 hour. Starting from $25 \mathrm{~g}$ of $\mathrm{HMF}$, HHD was isolated in $71 \%$ yield.

Recently, Dwivedi et al. examined cationic cyclopentadienylruthenium(II)-pyridylamine complexes for the conversion of HMF to HHD. ${ }^{47}$ The reactions were carried out in water in the presence of formic acid (12 eq. with respect to substrate) at $120{ }^{\circ} \mathrm{C}$. The $\eta$-5-Cp-Ru(II) complex bearing $N$-(pyridin-2ylmethyl)propan-1-amine as ligand ([Ru]-3) was found to be the most efficient; $69 \%$ selectivity towards HHD was achieved after 12 hours in the presence of $5 \mathrm{~mol} \%$ of the catalyst. In addition, the authors obtained purified product in $42 \%$ yield after column chromatography. Direct conversion of fructose under the same conditions resulted in $65 \%$ selectivity towards HHD after 6 hours.

\subsection{Conclusions on conversion of HMF to HHD}

Over the last 20 years, the conversion of HMF to HHD has been studied by several groups. It has been demonstrated that employing acidic conditions was the key parameter affecting selectivity towards HHD for this process. An overview of catalytic systems applied for the production of HHD is summarised in Table 1. In general, the utilisation of half-sandwich $\mathrm{Cp} * \mathrm{Ir}$ complexes provides the highest selectivities to HHD at the lowest catalyst loadings. However, the requirements of high dilution (to avoid the formation of humines) as well as the poor recyclability of the catalysts remain barriers on the way to large scale application.

\section{Applications of 1-hydroxyhexane- 2,5-dione}

There are a limited number of reports on the utilisation of HHD for the synthesis of useful products. In most cases, these were transformations of HHD formed in situ. This is a rapidly growing field.

\subsection{Preparation of cyclopentanone derivatives and follow-up products}

The intramolecular aldol condensation of HHD leads to the formation of five-membered ring compounds. It can occur via two different routes depending on the reaction conditions as described in Scheme 7. The group of Satsuma performed extensive research on the conversion of HMF to 3-hydroxycyclopentanone ( $\mathrm{HCPN}, 14)$ under acidic conditions and $\mathrm{H}_{2}$

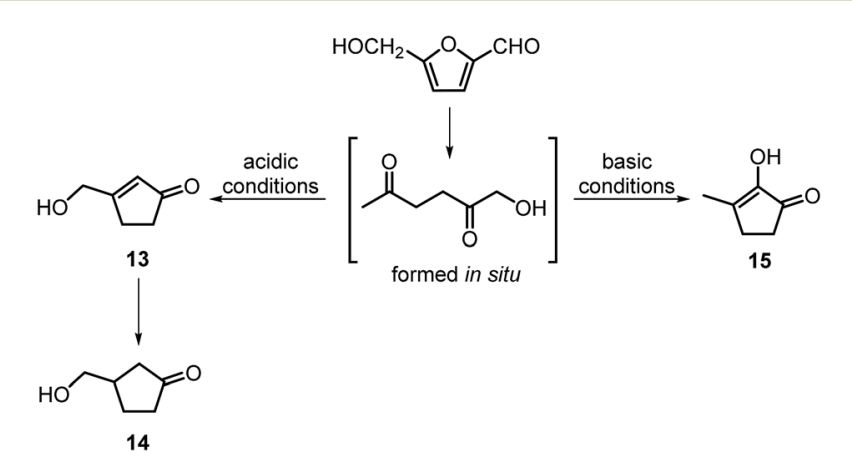

Scheme 7 Aldol condensation products starting from HHD. 
pressure. ${ }^{34,48,49}$ HCPN is an important chemical intermediate in the synthesis of polymers, pharmaceuticals and fuels. ${ }^{50,51}$ The first approach to the conversion of HMF to HCPN via HHD was based on the use of supported gold nanoparticles. ${ }^{34}$ Various metal oxides were examined as the supports under 80 bar of $\mathrm{H}_{2}$; they acted as a Lewis acids and catalysed the ring closure of HHD as it was formed. The highest reported selectivity towards HCPN was $86 \%$ after 12 hours using $1 \mathrm{wt} \%$ Au supported on niobium oxide at $140{ }^{\circ} \mathrm{C}$. Moreover, the activity of the catalyst did not decrease significantly after the second catalytic cycle (84\% selectivity). Following the reaction over time revealed the formation of HHD in 20\% yield for the first 6 hours and after this time HCPN was produced exclusively. Based on this result, a plausible mechanism was proposed for the conversion of HMF to HCPN (Scheme 8). Hydrogenation/hydrolytic ring opening of HMF leads to the formation of $\mathrm{HHD}$, which is consistent with the generally proposed mechanism. Subsequently, intramolecular aldol condensation of HHD occurs under acidic conditions resulting in the formation of 3(hydroxymethyl)cyclopent-2-en-1-one (HCPEN, 13), which is next hydrogenated to 14 . The same group investigated the effect of acid-base catalysis on the ring rearrangement of HMF by using a combination of a hydrogenation catalyst $\left(\mathrm{Pt} / \mathrm{SiO}_{2}\right)$ with acidic and basic metal oxides. ${ }^{47}$ The results of the experiments showed that basic metal oxides such as $\mathrm{La}_{2} \mathrm{O}_{3}$ and $\mathrm{CeO}_{2}$ produce HCPN in low yields ( $<25 \%$ yield), however, addition of acidic metal oxides (e.g. $\mathrm{Ta}_{2} \mathrm{O}_{5}, \mathrm{ZrO}_{2}, \mathrm{Nb}_{2} \mathrm{O}_{5}$ ) enhanced the yield of HCPN to around $80 \%$. The best catalytic performance was observed by using $1 \mathrm{wt} \% \mathrm{Pt} / \mathrm{SiO}_{2}$ together with $\mathrm{Ta}_{2} \mathrm{O}_{5}$ in water at $140{ }^{\circ} \mathrm{C}$ under 30 bar of $\mathrm{H}_{2}$ resulting in $82 \%$ yield of HCPN after 12 hours.

The formation of HCPN via HHD was also proposed by Perret et $a l .{ }^{52}$ To avoid the use of noble metal complexes, the catalytic activity of nickel supported on alumina was tested. A comparable yield of HCPN (81\%) was obtained after 6 hours at $140{ }^{\circ} \mathrm{C}$ and 20 bar of $\mathrm{H}_{2}$. Further research on the selective conversion of $\mathrm{HMF}$ to cyclopentanone derivatives was performed using $\mathrm{Cu}$ / $\mathrm{Al}_{2} \mathrm{O}_{3}$ and $\mathrm{Co} / \mathrm{Al}_{2} \mathrm{O}_{3}$ catalysts. ${ }^{53}$ When $26 \mathrm{wt} \%$ of $\mathrm{Cu} / \mathrm{Al}_{2} \mathrm{O}_{3}$ was used as a catalyst at $180^{\circ} \mathrm{C}$ and 20 bar of $\mathrm{H}_{2}$, the HCPN yield was $86 \%$ at full conversion after 6 hours. However, hydrogenative ring-rearrangement of $\mathrm{HMF}$ catalysed by 9 wt $\% \mathrm{Co} / \mathrm{Al}_{2} \mathrm{O}_{3}$ revealed the formation of 3-hydroxymethylcyclopentanol (HCPL), a hydrogenation product of HCPN. The highest HCPL yield of $94 \%$ was achieved at $140{ }^{\circ} \mathrm{C}$ and 20 bar of $\mathrm{H}_{2}$ after 48 hours. Ohyama et al. also reported the direct conversion of HMF to HCPL using a combination of $\mathrm{Pt} / \mathrm{SiO}_{2}$ and lanthanide oxides. ${ }^{49}$ High product yields (ca. 88\%) were obtained by applying $5 \mathrm{wt} \% \mathrm{Pt} / \mathrm{Nd}_{2} \mathrm{O}_{3}$ in water at $140{ }^{\circ} \mathrm{C}$ and 30 bar of $\mathrm{H}_{2}$ after 30 hours.

Deng, $\mathrm{Fu}$ and co-workers proposed a different mechanism for the formation of $\mathbf{1 4 .} .^{\mathbf{4 3}}$ They were able to show that BHMF undergoes a Piancatelli rearrangement under the influence of the Lewis acid to form 16, which subsequently is dehydrated and hydrogenated to obtain $\mathbf{1 4}$ (Scheme 8). They were able to obtain evidence for all the steps of the mechanism.

In contrast to acidic systems, intramolecular aldol condensation of HHD under basic conditions led to another cyclopentanone derivative: 2-hydroxy-3-methylcyclopent-2-enone (MCP, 15). ${ }^{38,43,45}$ MCP is a known naturally occurring flavour ingredient in roasted coffee ${ }^{54}$ and maple syrup. ${ }^{55}$ On the basis of these properties it has found commercial use in the food industry as a flavouring agent. Apart from its natural occurrence, MCP is commonly produced from adipic acid in a multistep reaction; however, the use of toxic reagents such as $\mathrm{Cl}_{2}$ and potentially carcinogenic $\mathrm{CH}_{3} \mathrm{I}$ is required for this process. ${ }^{56}$ Therefore, the development of a bio-based route to MCP is highly desired.

Deng, Fu and co-workers discovered the preparation of MCP from HHD under basic conditions. ${ }^{43}$ A typical experiment was performed with $25 \mathrm{~mol} \% \mathrm{KOH}$ in refluxing water. An MCP yield of $45 \%$ was obtained after stirring the reaction mixture for 40 minutes. Yang and co-workers examined the conversion of HHD to MCP in the presence of different bases. ${ }^{38}$ The addition of solid base $\mathrm{Ca}-\mathrm{Al}(200 \mathrm{mg})$ to a refluxing aqueous solution of HHD (0.1 M) led to 88\% selectivity toward MCP after 6 hours. In addition, neutralisation was not required, since the $\mathrm{pH}$ value of the aqueous solution after reaction was neutral. Other solvents, such as $n$-butanol, ethanol and MIBK were also tested but did not lead to any improvements in MCP selectivities. A reaction mechanism was proposed as described in scheme 9.

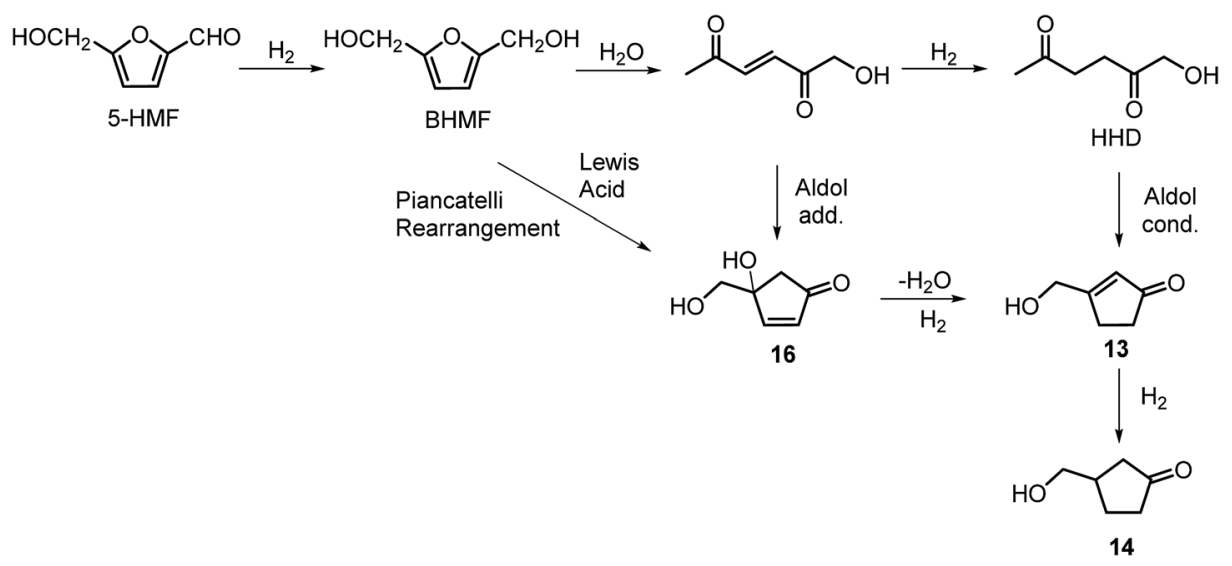

Scheme 8 Plausible mechanism for the conversion of HMF to HCPN via HHD. 


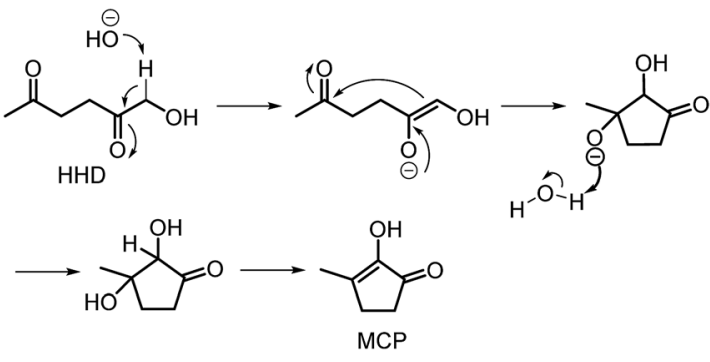

Scheme 9 Base-promoted intramolecular aldol condensation of HHD.

Deprotonation of HHD under basic conditions occurs at the $\alpha$ hydroxy position. In the next step, the enolate reacts intramolecular with the other ketone group to form the $\alpha, \beta$ bishydroxy-cyclopentanone derivative, followed by dehydration to give MCP. In addition, the direct synthesis of MCP from HMF under optimised conditions using $\mathrm{Pd} / \mathrm{Nb}_{2} \mathrm{O}_{5}$ and $\mathrm{Ca}-\mathrm{Al}$ was reported. The product was isolated in $58 \%$ yield.

Wozniak et al. examined the role of the base and solvent in the aldol condensation reaction of $\mathrm{HHD}$ at $60{ }^{\circ} \mathrm{C} .{ }^{44}$ An isolated MCP yield of $72 \%$ was achieved in aqueous $\mathrm{KOH}$ solution after 15 minutes. Alternatively, an $80 \%$ yield at full conversion of the starting material was obtained after 5 min in a THF solution of $\mathrm{KO}^{t} \mathrm{Bu}$. The authors also established a one-pot synthesis of MCP directly from HMF via HHD as an intermediate (Scheme 10). The application of the optimised conditions afforded 55\% isolated yield of MCP in a one-pot reaction. In addition, they reported the X-ray structure of MCP (Fig. 5).

Furthermore, MCP was converted to a number of valuable products as described in Scheme 11. For example, the fully hydrogenated form of MCP, 3-methyl-1,2-cyclopentanediol (17) was obtained in near quantitative yield as a mixture of isomers by using the commercially available Ru-MACHO-BH catalyst (Scheme 11, eqn (a)). The oxidative carbonylation of diol 17 has

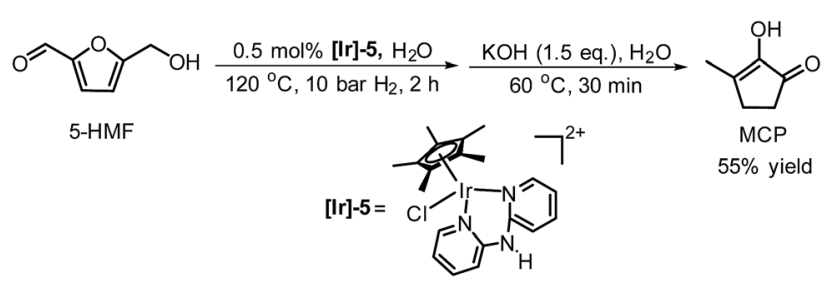

Scheme 10 A one-pot synthesis of MCP from HMF.

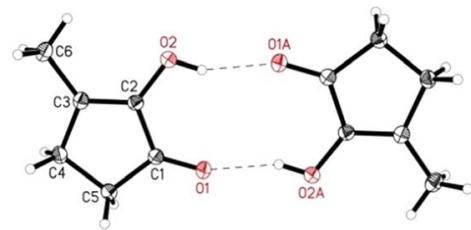

Fig. 5 ORTEP representation of MCP showing intermolecular $\mathrm{O}-\mathrm{H} \cdots \mathrm{O}$ hydrogen bonds.

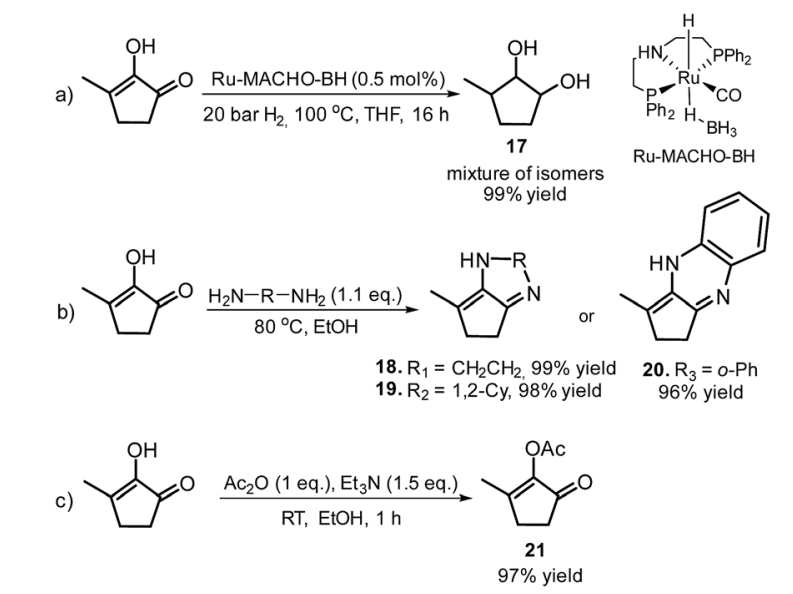

Scheme 11 Conversion of MCP into valuable biomass-based products.

been reported to lead to the formation of the cyclic carbonates, which are important intermediates in the synthesis of pharmaceuticals, polymers and agrochemicals. ${ }^{57}$ The application of aliphatic and aromatic diamines in the reaction with MCP led to excellent yields of the corresponding $\alpha, \beta$-unsaturated heterocyclic imines and a quinoxaline derivate (Scheme 11, eqn (b), 18-20). Quinoxalines are known intermediates for the manufacturing of pharmaceuticals due to their antiviral, anticancer and antidepressant properties. ${ }^{58}$ Another possible useful synthetic approach is the transformation of MCP to the corresponding enol acetate (21, Scheme 11, eqn (c)), which is a starting material for the synthesis of dihydrojasmone, a fragrance used in perfumes. ${ }^{59}$

\subsection{Synthesis of pyrroles}

In another publication by de Vries and co-workers, the main focus was on the utilisation of the diketone moiety of HHD. ${ }^{46}$ 1,4-diketones are common substrates in the Paal-Knorr synthesis for the production of pyrroles in reaction with primary amines. Usually, weakly acidic conditions are required for this transformation. However, the authors achieved the synthesis of $\mathrm{N}$-substituted 2-hydroxymethyl-5-methyl-pyrroles from HHD and a variety of primary amines in ethanol as solvent at room temperature, without catalyst (Scheme 12).

In general, most of the $N$-alkyl and $N$-benzyl substituted pyrroles were isolated with excellent yields after 5-25 minutes (Fig. 6). In case of more sterically hindered amines, like cyclopentylamine and aniline derivatives prolonged reaction times (up to $48 \mathrm{~h}$ ) were required. However the utilisation of anilines bearing electron-donating groups led to the full conversion of

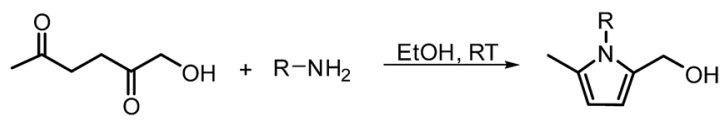

Scheme 12 The Paal-Knorr synthesis of $N$-substituted pyrroles starting from HHD. 

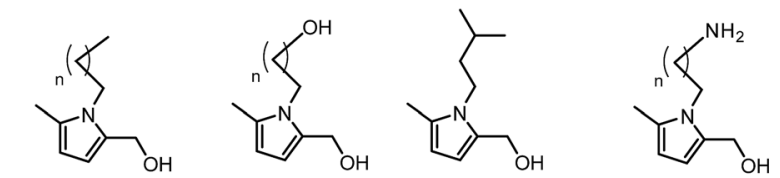

$\mathrm{n}=1,15 \mathrm{~min}, 98 \%$ yield $\mathrm{n}=2,15 \mathrm{~min}, 99 \%$ yield $n=4,20 \mathrm{~min}, 97 \%$ yield $n=4,20 \mathrm{~min}, 98 \%$ yield $n=6,20 \mathrm{~min}, 96 \%$ yield
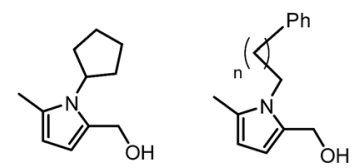

$25 \mathrm{~min}, 97 \%$ yield

$n=5,15 \mathrm{~min}, 66 \%$ yield

$$
48 h, 80 \% \text { yield }
$$
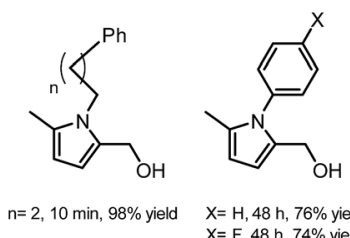

$X=H, 48 h, 76 \%$ yield $X=F, 48 h, 74 \%$ yield $\mathrm{X}=\mathrm{NH}_{2}, 10 \mathrm{~h}, 82 \%$ yield $\mathrm{X}=\mathrm{SCH}_{3}, 48 \mathrm{~h}, 78 \%$ yield

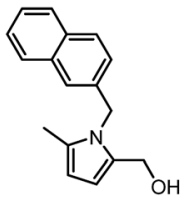

$30 \mathrm{~min}, 88 \%$ yield

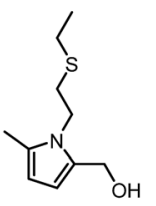

$30 \mathrm{~min}, 99 \%$ yield

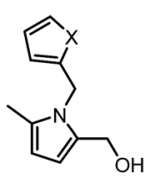

$X=0,1 \mathrm{~h}, 96 \%$ yield

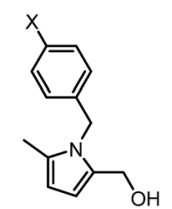

$X=H, 25$ min, $97 \%$ yield $\mathrm{X}=\mathrm{OM}, 20 \mathrm{~min}, 99 \%$ yield $\mathrm{X}=\mathrm{OMe}, 10 \mathrm{~min}, 99 \%$ yie
$\mathrm{X}=\mathrm{CF}_{3}, 1 \mathrm{~h}, 96 \%$ yield

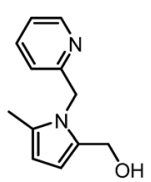

$10 \mathrm{~min}, 98 \%$ yield
Fig. $6 N$-substituted pyrroles derived from HHD.

HHD in shorter reaction times (up to $20 \mathrm{~h}$ ). In addition, a series of pyrroles containing heteroatoms such as sulfur, oxygen and nitrogen was synthesised in up to $99 \%$ isolated yields. On the basis of these results, the described Paal-Knorr synthesis meets the Click Reaction ${ }^{60}$ requirements as it provides the products in near quantitative yields in very short reaction times and proceeds under mild conditions in a benign solvent. Moreover, in most cases, the only by-product of the reaction is water and the pure product was simply isolated by evaporation of the solvent.

\subsection{Others}

The hydrogenation of HMF often resulted not only in the formation of HHD, but also in its fully hydrogenated form: 1,2,5hexanetriol $(1,2,5-\mathrm{HT})$. In 1991, Descotes was the first who reported the synthesis of 1,2,5-HT directly from HMF using heterogeneous $\mathrm{Ru} / \mathrm{C}$ as a catalyst. ${ }^{31}$ The same compound has been described as one of the by-products in prolonged hydrogenation of HMF catalysed by supported metals. ${ }^{61,62}$ Melián-Cabrera and co-workers obtained 1,2,5-HT by hydrogenating BHMF using $\mathrm{Rh}-\mathrm{Re} / \mathrm{SiO}_{2}$ as catalyst with $92 \%$ selectivity. ${ }^{63} \mathrm{Xu}$ and co-workers described the hydrogenation of HHD in aqueous solution, which provided isolated 1,2,5-HT yield of 95\% after 4 hours. ${ }^{37}$ The reaction was carried out in the presence of $5 \mathrm{wt} \% \mathrm{Ru} / \mathrm{C}$ under 40 bar $\mathrm{H}_{2}$ at $120^{\circ} \mathrm{C}$. Wozniak et al. developed a method for synthesis of 1,2,5-HT starting from HHD using homogeneous catalysis. ${ }^{64} \mathrm{~A}$ near quantitative yield of triol was achieved after 18 hours at $100{ }^{\circ} \mathrm{C}$ with 30 bar of $\mathrm{H}_{2}$ using $0.5 \mathrm{~mol} \%$ Ru-MACHO-BH and isopropanol as the solvent (Scheme 13). Moreover, the authors showed that 1,2,5-HT can be further converted into useful products in the presence of rhenium(vII) oxide. Rhenium has received increasing interest caused by the high activity in many transformations, especially the deoxydehydration reaction
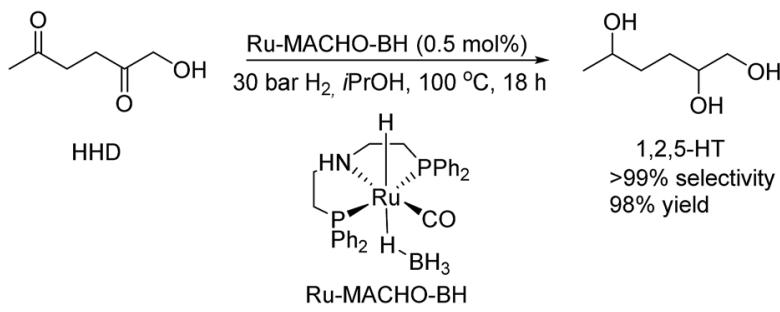

1,2,5-HT $>99 \%$ selectivity $98 \%$ yield

Ru-MACHO-BH

Scheme 13 Homogeneous hydrogenation of HHD.

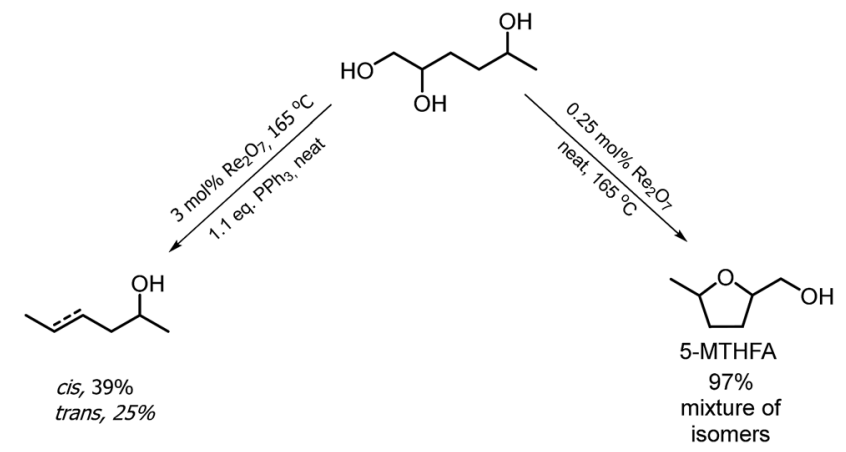

Scheme 14 Rhenium catalysed transformations of 1,2,5-hexanetriol.

(DODH) of vicinal diols to produce alkenes in the presence of a reductant. ${ }^{65-67}$ This is a very promising approach for oxygen removal from biomass-derived platform chemicals without losing any carbon atoms. De Vries and co-workers described DODH of $1,2,5-\mathrm{HT}$ under neat conditions at $165{ }^{\circ} \mathrm{C}$ in the presence of $3 \mathrm{~mol} \% \mathrm{Re}_{2} \mathrm{O}_{7}$ and 1.1 eq. $\mathrm{PPh}_{3}$ as a reductant. ${ }^{64}$ A mixture of cis- and trans-4-hexen-2-ol as the main products was obtained (Scheme 14). The same $\mathrm{Re}_{2} \mathrm{O}_{7}$ catalysed reaction in the absence of the reductant resulted in the selective formation of the cyclic product 5-methyltetrahydrofurfuryl alcohol (5-MTHFA). This compound has been described as a potentially useful fuel additive and has been reported as the main product of 5-methylfurfural hydrogenation. ${ }^{\mathbf{6 8 , 6 9}}$

\section{Conclusions}

In conclusion, this review summarises both the state of art for HHD synthesis including the mechanistic aspects of its formation, as well as the recent progress in the application of HHD as a building block for useful chemicals. A broad range of compounds was synthesised from it, which can serve in the production of consumer products of the chemical industry including pharmaceuticals, food additives, agrochemicals and transportation fuels. However, the key to the success of HHD will be the development of an production method at larger (commercial) scale for HMF. This would further boost the interest in the chemistry of HHD, which has the potential to become one of a new generation of Platform Chemicals.

\section{Conflicts of interest}

There are no conflicts to declare. 


\section{Acknowledgements}

We thank the Leibniz Foundation for financial support (SAWLIKAT-1 523). We thank Martyna Wozniak for the TOC illustration.

\section{References}

1 M. A. Rubio Rodriguez, J. De Ruyck, P. Roque Diaz, V. K. Verma and S. Bram, Appl. Energy, 2011, 88, 630-635.

2 W. P. Nel and C. J. Cooper, Energy Policy, 2009, 37, 166180.

3 S. Shafiee and E. Topal, Energy Policy, 2009, 37, 181-189.

4 B. Kamm, P. R. Gruber and M. Kamm, Biorefineries: Industrial Processes and Products, in Ullmann's Encyclopedia of Industrial Chemistry, Wiley-VCH, Weinheim, Germany, 2012.

5 T. Werpy and G. Petersen, Top Value-Added Chemicals from Biomass, Vol. I: Results of Screening for Potential Candidates from Sugars and Synthesis Gas, U.S. Department of Energy (DOE) by the National Renewable Energy Laboratory, Golden, CO, 2004.

6 A. Corma, S. Iborra and A. Velty, Chem. Rev., 2007, 107, 24112502.

7 A. J. Ragauskas, C. K. Williams, B. H. Davison, G. Britovsek, J. Cairney, C. A. Eckert, W. J. Frederick Jr, J. P. Hallett, D. J. Leak, C. L. Liotta, J. R. Mielenz, R. Murphy, R. Templer and T. Tschaplinski, Science, 2006, 311, 484-489.

8 P. J. Deuss, K. Barta and J. G. de Vries, Catal. Sci. Technol., 2014, 4, 1174-1196.

9 J. G. de Vries, Chem. Rec., 2016, 16, 2787-2800.

10 R. D. Perlack, L. L. Wright, A. F. Turhollow, R. L. Graham, B. J. Stokes and D. C. Erbach, Biomass as a feedstock for a bioenergy and bioproducts industry: the technical feasibility of a billion-ton annual supply, US Department of Agriculture, Washington, DC, 2005.

11 C.-H. Zhou, X. Xia, C. X. Lin, D. S. Tong and J. Beltramini, Chem. Soc. Rev., 2011, 40, 5588-5617.

12 J. J. Bozell and G. R. Petersen, Green Chem., 2010, 12, 539554.

13 R. J. van Putten, J. C. van der Waal, E. de Jong, C. B. Rasrendra, H. J. Heeres and J. G. de Vries, Chem. Rev., 2013, 113, 1499-1597.

14 L. T. Mika, E. Cséfalvay and A. Németh, Chem. Rev., 2018, 118, 505-613.

15 T. Wang, M. W. Nolte and B. H. Shanks, Green Chem., 2014, 16, 548-572.

16 A. A. Rosatella, S. P. Simeonov, R. F. M. Frade and C. A. M. Afonso, Green Chem., 2011, 13, 754-793.

17 G. Düll, Chem.-Ztg., 1895, 19, 216-217.

18 J. Kiermayer, Chem.-Ztg., 1895, 19, 1003-1006.

19 B. Liu and Z. Zhang, ChemSusChem, 2016, 9, 2015-2036.

20 I. Delidovich, P. J. C. Hausoul, L. Deng, R. Pfützenreuter, M. Rose and R. Palkovits, Chem. Rev., 2016, 116, 1540-1599.

21 S. W. Teong, G. Yi and Y. Zhang, Green Chem., 2014, 16, 2015-2026.
22 T. Buntara, S. Noel, P. H. Phua, I. Melián-Cabrera, J. G. de Vries and H. J. Heeres, Angew. Chem., Int. Ed., 2011, 50, 7083-7087.

23 J. Shen, H. Chen, K. Chen, Y. Qin, X. Lu, P. Ouyang and J. Fu, Ind. Eng. Chem. Res., 2018, 57, 2811-2818.

24 F. Jie, S. Jinshan, C. Hao, L. Xiuyang and O. Pingkai, CN106749130, 2017.

25 T. R. Boussie, E. L. Dias, Z. M. Fresco and V. J. Murphy, Production of adipic acid and derivatives from carbohydratecontaining materials, WO2010144873, 2010to Rennovia inc.

26 T. R. Boussie, G. M. Diamond, E. Dias and V. Murphy, in Chemicals and Fuels from Bio-Based Building Blocks, ed. F. Cavani, S. Albonetti, F. Basile and A. Gandini, Wiley-VCH, Weinheim, 2016, pp. 152-171.

27 S. Krawielitzki and T. M. Kläusli, Ind. Biotechnol., 2015, 11(1), 6-8.

28 K. I. Galkin, E. A. Krivodaeva, L. V. Romashov, S. S. Zalesskiy, V. V. Kachala, J. V. Burykina and V. P. Ananikov, Angew. Chem., Int. Ed., 2016, 55, 8338-8342.

29 (a) G. J. M. Gruter and F. Dautzenberg, WO2007104514, 2007, to Avantium International BV; (b) A. S. Dias, R.-J. van Putten and G. J. Gruter, WO2012091570, 2012, to Furanix Technologies; (c) J. C. van der Waal, E. Mazoyer, H. J. Baars and G. J. M. Gruter, in Liquid Phase Aerobic Oxidation Catalysis: Industrial Applications and Academic Perspectives, ed. S. S. Stahl and P. L. Alsters, Wiley-VCH Verlag GmbH \& Co. KGaA, 2016, pp. 311-329.

30 M. Mascal and E. B. Nikitin, Angew. Chem., Int. Ed., 2008, 47, 7924-7926.

31 V. Schiavo, G. Descotes and J. Mentech, Bull. Soc. Chim. Fr., 1991, 128, 704-711.

32 G. C. A. Luijkx, N. P. M. Huck, F. van Rantwijk, L. Maat and H. van Bekkum, Heterocycles, 2009, 77, 1037-1044.

33 J. Ohyama, A. Esaki, Y. Yamamoto, S. Arai and A. Satsuma, RSC Adv., 2013, 3, 1033-1036.

34 J. Ohyama, R. Kanao, A. Esaki and A. Satsuma, Chem. Commun., 2014, 50, 5633-5636.

35 F. Liu, M. Audemar, K. De Oliveira Vigier, J.-M. Clacens, F. De Campo and F. Jérôme, ChemSusChem, 2014, 7, 2089-2095.

36 F. Liu, M. Audemar, K. De Oliveira Vigier, J.-M. Clacens, F. De Campo and F. Jérôme, Green Chem., 2014, 16, 4110-4114.

37 Y. Yang, Z. Du, J. Ma, F. Lu, J. Zhang and J. Xu, ChemSusChem, 2014, 7, 1352-1356.

38 Y. Duan, M. Zheng, D. Li, D. Deng, L.-F. Ma and Y. Yang, Green Chem., 2017, 19, 5103-5113.

39 Z. Xu, P. Yan, W. Xu, X. Liu, Z. Xia, B. Chung, S. Jia and Z. C. Zhang, ACS Catal., 2015, 5, 788-792.

40 K. Gupta, D. Tyagi, A. D. Dwivedi, S. M. Mobin and S. K. Singh, Green Chem., 2015, 17, 4618-4627.

41 A. D. Dwivedi, K. Gupta, D. Tyagi, R. K. Rai, S. M. Mobin and S. K. Singh, ChemCatChem, 2015, 7, 4050-4058.

42 W.-P. Wu, Y.-J. Xu, R. Zhu, M.-S. Cui, X.-L. Li, J. Deng and Y. Fu, ChemSusChem, 2016, 9, 1209-1215.

43 Y.-J. Xu, J. Shi, W.-P. Wu, R. Zhu, X.-L. Li, J. Deng and Y. Fu, Appl. Catal., A, 2017, 543, 266-273.

44 Z. Xu, P. Yan, H. Li, K. Liu, X. Liu, S. Jia and Z. C. Zhang, ACS Catal., 2016, 6, 3784-3788. 
45 B. Wozniak, A. Spannenberg, Y. Li, S. Hinze and J. G. de Vries, ChemSusChem, 2018, 11, 356-359.

46 B. Wozniak, Y. Li, S. Hinze, S. Tin and J. G. de Vries, Eur. J. Org. Chem., 2018, 2009-2012.

47 A. D. Dwivedi, V. K. Sahu, S. M. Mobin and S. K. Singh, Inorg. Chem., 2018, 57, 4777-4787.

48 J. Ohyama, R. Kanao, Y. Ohira and A. Satsuma, Green Chem., 2016, 18, 676-680.

49 J. Ohyama, Y. Ohira and A. Satsuma, Catal. Sci. Technol., 2017, 7, 2947-2953.

50 T. Kitahara, Y. Warita, M. Abe, M. Seya, Y. Takagi and K. Mori, Agric. Biol. Chem., 1991, 55, 1013-1017.

51 P. Marcé, Y. Díaz, M. I. Matheu and S. Castillón, Org. Lett., 2008, 10, 4735-4738.

52 N. Perret, A. Grigoropoulos, M. Zanella, D. T. Manning, J. B. Claridge and M. J. Rosseinsky, ChemSusChem, 2016, 9, 521-531.

53 R. Ramos, A. Grigoropoulos, N. Perret, M. Zanella, A. P. Katsoulidis, T. D. Manning, J. B. Claridge and M. J. Rosseinsky, Green Chem., 2017, 19, 1701-1713.

54 M. A. Gianturco, A. S. Giammarino and R. G. Pitcher, Tetrahedron, 1963, 19, 2051-2059.

55 V. J. Filipic, J. C. Underwood and C. O. Willits, J. Food Sci., 1965, 30, 1008-1015.

56 C. M. Leir, J. Org. Chem., 1970, 35, 3203-3205.

57 S. P. Chavan and B. M. Bhanage, Tetrahedron Lett., 2014, 55, 1199-1202.
58 R. Sarges, H. R. Howard, R. C. Browne, L. A. Label and P. A. Seymour, J. Med. Chem., 1990, 33, 2240-2254.

59 J. L. E. Erickson and F. E. Collins Jr, J. Org. Chem., 1965, 30, 1050-1052.

60 H. C. Kolb, M. G. Finn and K. B. Sharpless, Angew. Chem., Int. Ed., 2001, 40, 2004-2021; Angew. Chem., 2001, 113, 20562075.

61 R. Alamillo, M. Tucker, M. Chia, Y. Pagán-Torres and J. Dumesic, Green Chem., 2012, 14, 1413-1419.

62 Y. Duan, J. Zhang, D. Li, D. Deng, L.-F. Ma and Y. Yang, RSC Adv., 2017, 7, 26487-26493.

63 T. Buntara, I. Melián-Cabrera, Q. Tan, J. L. G. Fierro, M. Neurock, J. G. de Vries and H. J. Heeres, Catal. Today, 2013, 210, 106-116.

64 B. Wozniak, Y. Li, S. Tin and J. G. de Vries, Green Chem., 2018, 20, 4433-4437.

65 S. Raju, M.-E. Moret and R. J. M. Klein Gebbink, ACS Catal., 2015, 5, 281-300.

66 J. R. Dethlefsen and P. Fristrup, ChemSusChem, 2015, 8, 767775.

67 S. Tin and J. G. de Vries, in Science of Synthesis: Catalytic Reduction in Organic Synthesis, ed. J. G. de Vries, Georg Thieme Verlag KG, Stuttgart, 2018, vol. 1, pp. 229-243.

68 M. Chatterjee, T. Ishizaka and H. Kawanami, Green Chem., 2014, 16, 1543-1551.

69 C. Li, G. Xu, X. Liu, Y. Yhang and Y. Fu, Ind. Eng. Chem. Res., 2017, 56, 8843-8849. 